\title{
IX International Conference "Computer-Aided Design, Computer-Aided Manufacturing, and Product Data Management Systems (CAD/CAM/PDM-2009)"
}

DOI: $10.1134 / \mathrm{S} 0005117909090136$

IX International Conference "Computer-Aided Design, Computer-Aided Manufacturing, and Product Data Management Systems (CAD/CAM/PDM-2009)" will be held on October 20-22, 2009 at the Trapeznikov Institute of Control Sciences (Moscow, Russia).

\section{Conference Subject Areas:}

- Structuring of the hardware and software design and control facilities. Means of interaction, data structures, international standards.

- Computer graphics and CAD/CAM/PDM systems in education (disciplinary education programs, methodological materials, testing). Virtual reality facilities in industrial systems.

- Integrated production systems and process control. PDM systems.

- Design in machine building and construction.

- Design in radio electronics.

\section{Organizers:}

- Russian Academy of Sciences

- RF Ministry of Education and Science

- Trapeznikov Institute of Control Sciences, RAS

- International Academy of Informatization

- Khrunichev State Research and Production Space Center

- Moscow Technical University of Communication and Informatics (MTUCI)
- Rocket and Space Corporation "Energia" (RSC)

- American Charitable Foundation for the Development of Information Technology for Education and Science - MSTU "Stankin"

\section{Deadlines:}

September 25, 2009-Application for participation at the conference and/or exhibition, transfer of the admission fee, abstracts (at most one A-5 paper).

October 1, 2009-Full texts of papers.

Applications, abstracts, and papers are sent to the e-mail address: conf18@spm.ipu.ru

Current Information (Application forms, guidelines, etc.): http://lab18.ipu.rssi.ru

Languages: Russian and English.

\section{Organizing Committee:}

CAD/CAM/PDM-2009 Organizing Committee, Trapeznikov Institute of Control Sciences, Russian Academy of Sciences, 65 Profsoyuznaya St., Moscow, 117997, Russia.

Chairman: Dr. Sci. Evgenii I. Artamonov.

Scientific secretary: Cand. Sci. Sergei V. Smirnov. 